\title{
A Vocação Medica
}

\author{
Conferencia realisada sob os auspi- \\ cios do Centro Academico "Oswaldo \\ Cruz", no salão do Jardim da In- \\ fancia pelo Prof. Dr. Fernando $\mathrm{Ma}$ - \\ galhães, lente cathedratico da $\mathrm{Fa}$ - \\ culdade de Medicina do Rio de \\ Janeiro.
}

Meus quenidos camamadas. Aśsim vos digo no grande reconhec1mento pelo vosso favor demasiado. Accedi a honroso oonvite que me fizestes e vim, itambem peila seducção da vossa terra, acolher-me ao agazalho da vossa sympathia.

Alo ouvir o som vibrante de vozes enthusiasticas de gente nova, costumo sentir dentro ide mim a evocação de um tempo que passou fugidłio, deixando o sulco fundo de uma alegria sã e, tal é o resurgimento da idadie sepulta, que, num instante, transporto-me com as mesmas illusões de outróna, á ifascinação da vossa bemidiata fantasia. Abro os braços, no gesto symbolico de um grande affecto, para receber a fortuna siem par da 'vossa mocidade. Que ella se infiltre, poderosamente, no sombrio remanso de minha duvida ıdolorida, nesta hora suprema em que o olhar interrogativo e ancioso não consegue dissipar o presagio das granides tristezas. Alo vosso dado, a menos terei o conffonto de vossa illimitada esperança, gozarei a grandeza de vosisa temeridade risonha, conquistarei a inquebrantavel confiança dio vosso glorioso futuro, sentirei o deslumbramento dessa visão arrebatadiora, mais opulentamente dio que o olhar sem luz que, no milagre divino, abrisse de subito os olhos ao formoso espectaculo das maravilhas do mundo.

Boa e suave consolação que é. o vosso convivio para quem, na vida madura, possante e penosa, illude os seus desenganos com a alegria descuidada da vossa juventude.

Não lembro o momeinto para: antecipar a realidiade sombria, senão para reconhecer a extensão de vossa genenosidade, itanto em todos nós, baitidos pelio tempo, ja sabendo o delstino que nos cumpre e a tarefa que nos cabe, é immenso o encanto pelo conho da idaide de ouro tão longinqua e tão cheia de reicordações.

Tenho vivido no callor idesta illusã̃o como se fôra dios vossos, na hora em que sois da minha companhia. Viai a gente pelo caminho duro e fatigante da vida trabalhosa, a olhar sempre o que já passou; pela manhã, a madrugada que nos despenta ś6 lembra a extenisão ıda tarefa que a sorte mos impoz; o sol die tod.o o dia quebranta-nos rudemente e queima sem piedadie o quie se lida; á noite, só nos repou- 
sa depois de repassar pela nossa imaginação o que já se andou na duvida, dio quanto ainda resta da jornada. Não assim a vossa fantasia, sempre voltada para o ique ha de vir. Da alvorada só enitendeis a natureza que acorda no rumor de sua exuberancia festiva; o dia enche die luz o explendior de vossas ambições; a noite realiza no sonho a ousardia dos viossos idesejos. E tudo íssio se sente na irradiação do vosiso olhar, no impuliso dos vossos corações, no enthusiasmio de vosaas palavras, na serenidade do vossa impeto, na certieza de vosso brio, na gloria die vossos triumphos. Transportais tudo isto para junto do desanimo e fazeils o milagre do rejuvenescimento 1 , de tal forma, que a mim, nem sei como, idais a coragem bastante para, penetrandio no fundo die vossas conøciencias, buscar, sentir a inspiração eterna que acceniderá em caida um de vós o fogo sagradio de voicação profissional.

Deveis entrar na vida, meus jovens amigos, com a segurança desta uncção vocativa.

No evangelho die S. Matheus ha um quadrno digno de melditação: uma pobre mãi anciosa pedie ao Christo que the guande os dous filhos, um de cada lado, no dila em que o seu reino vier. Foi pouco antes da triste jornada do Jandim idas Oliveiras $\theta$ o Nazareno recebeu a supplica maternal perguntando aos dous jovens, se elles póderiam beber dio calice que elle proprio haveria de sorver. No ardior da sua decisão, ambos responderam singelamente - Possumus! Nós podemos, nós estamos promptos.

U.m dia tereis die respoinder da mesma fónma e a vós miesmos. Estareis promptos para executar a maxima hippocratica, synthetizando a immensa tarefa profissional, quando "á brevidade dia vida se contrapõe a vastidão dos conhecimentos humanos, a passagem fugaz̃ da occasião, a autoridalde tão enganosa da experiencia e a forçosa vacillação do espirito humano." A vida é breve, a arte é longa, a occasião fugidia, a experiencia enganadora, o juizo idifficil.

A vida é brevie. Sejja ellia um soluço immenso, uma ancia continua, um gozo ephemero, é sempre um rapido insitante no tempo talvez infinito. Sel-o-ha ainda mais a vossa, votada a canseira sublime die zelar pela do vosiso semelhante, solicitada pelo soffrimento que vos olhará como uma salvação miraculosa, e mais delle serão os vossos trabalhos e os vossos dazeres, ital a anciedadie pelo voeso consolo, pelo vosso cuidado, pela voissa palavra. Quem quer que se sinta ameaçado, torturado de dor ou transido de morte, implorará a misericordia lenitiva da solicitude, em busca do enganoso alento que até consegue fazer crepitar de esperanças a vida crepuscular. Melhor sabereis, então, como se vos offerecerá a opportunidade de gastar a vossa vida pela dos outros, tão insensivelmente que a velhice, se a ella 
se chega, será a sorpreza de um desicanso ou de um abandono, offerecendo nos seus dious fios, ainida, a recordação die todos os episodios dolentes que calaram as alegiras da mocidade.

A vida será, sem duvida, por esse tado, sem o sentirdies, tristemente curta, mas o contacto diario das vidas que vos fogem e das que tão penosamente conservaes, ha die vos dizer a todo instante, a riqueza fragil que ella representa, tanto se desmorona subitamiente em plena cruciação, apaga-se montiçamentie em plena decadencia. A profissão não vos permittirá, mesmo no fragor do mundio feliz e pujante, esquecer a rapildez de uma existencia que quasi não vos pertence. A vocação impõe o sacrificio e o idesprendimento; mesmo dentro da avidez ıdos tempos modiernos, as mais utilitarias não conseguem li-. vrar-se da exhaustão e do exgotamento. $E$ a vida vôa, assim entre o sentimento pela pena que se vê e a preoccupação pelo mal que se sente esquecida no continuo cuidar de tantas que ameaçam fugir, e tão esquecida, que não se a sente, através do labor e da fadiga, senão quando, tambem periclitante, ella cahe na molestia ou descamba no infortunio.

Curta vida de grandes decepções, de muitas dores, de repetidos tormentos, de alegrias passageiras. Tão curta que nos escapa, no mais seguro do nosso cuidado, a ique desponta, a que irradia, a que declina, quando, num sunto de forca, o mal, irremediavel e tyranno apaga o viço do conpo e a formosura do espirito. Assim, mesmo breve, fragil, cabe-nos guardal-a e defendel-a, como se fosse noseo o podier sobrenatural de eternizar o perecivel. Ninguem se conforma com a jidéa da curteza do precioso dom de viver; idepositarios deste thesouno, não haverá pendão se ellie escapa de viossias mãos zelosa e fieis, mesmo que grande seja o esicrupulo do vosso desvelo e inevitarel o golpe cruei da fatalidade.

Breve a vida, para os proprios desejos e para a anciedade de a sentir mais demoradamente, mais intimamente. Encuntará ain da o tempo ligeiro a obrigação de recolher as magoas alheias e de soffrer as dores extranhas. Vida breve que foge na initensidadle do trabalho, que passa na continuidade do esforço, que corre na constancia da preoccupação, que voa na tenacidade da luta, que se sacrifica no convivio das atribulações, que se annuvia no contacto com o soffrimento, que se tolda de pezares, que descamba em tristes icrepusculos e que se acaba em melancolicas recordações. 'Mas tambem vida curta que se apura na dedicação, que se adorna na piediade, que sie aperfeiçôa na misericordia, que se eleva no desprendimento, que se ennobrece na solidariedadie, que se santifica no sacrificio, que passa impavida e suave, por entre as dores e as esperanças, para terminar bem aventuraida e jusita no meilo das bençãos e das lamentações. 
A arte é longa, tão longa quanto a humanidade eoffredora. Sois os legatarios de uma grande herança de sabedoria, que os seculos accumularam; a vastidão das doutrinas máis desvienda a immensidade do desconhecido. ICom a primeira dor surgio a primeiro allivio; rolaram os tempos, gerações se succeideram, e, com o objectivo de curar a molestia, profundo é o enisinamento, interminavel o estudo. Ao começar o aprendizado, necebeis o que se tem como certo ou provavel nos diominios da arte, tudio representando a collaboração veneravel e pertinaz de muitas idadies, construind'o idéas em cujos escombros novas theorias se levanitam. Leia-se cuidadosamente a itradição dessa artie, aprenda-se a respeitar a grande obra collectiva que é, na historia humana, a tarefia ininterrupta de vencer o mal: doutrinas e principios que a imaginação creou e o soffrimento repelio, praticas e regras que a razão suppõe intangiveis e a molestia prova insubsistentes, idéas e theorias que a vontadie acredita victoriosas $\theta$ a eternidade da dor affirma insignificantes, opiniões e leis que a vaidade impõe como infalliveis e o itempo afasta como inuteis, escolars e dogmas que surgem dominadores e que desapparecem mais rapidamente do que a fama de uma geração.

Longa arte, grande de sabedoria e maior ainda de mysterio. Passassem embora millenios, ha muito que desvendar no comhecimentó do corpo e-do espirito do homem; uma conquista definitiva tem um acervo de provações e um estendal de pezares. Um marco do progresso só se planta ao fim de uma longa estrada de cruzes. Ha deseeperós que não findam, angustilas que não cessam, infortunios perennes, martyrios longos, maldições constantes, que raro conduzem á victoria glorificadora e que sempre transitam pelo caminho dos desenganos.

Tão longa a arte que, apezar de suas conquistas e de suas descobertas, ainda não se libertou do maravilhoso. Haveís de sentir na profíssão qualquer cousa de sobrenatural que illumine as trevas do diagnostico e devaissa, com o olhar do eleito, o prognostico impenetravel. Maravilhosa creação será a vossa, forrada dessa graça divinatoria, ao mesmo tempo favor da natureza privilegiada e premio da fecunda meditação.

Arte longa, que ensina a ler o livro da vida e a decifrar os enigmas da morte; que empresta halos de predestinado e transfiguração de santo; que deiscortina o invizivel e alcança o insondavel; que dá a razão aguçada e forte visão sobrenatural e extramha; que apura o entendimento em descoberta do mal omnimodo e esquivo; que se sente seduzida pelo segredo e pelo desconhecido; arte do allivio, da consolação, da ternura, da clemencia; arte de ouvir e de esquecer, de sentir e de perdoar, de amar e de soffrer; arte de mudar a lagrima em riso, a dôr em beatitude, a agonia em salvação; arte de receber o primeiro vaigido e de recolher o ultimo alento; 
arte de prolongar a vida e de ouavisar a morte; arte dos semideusers de outr'ora e dos grandes sabios de hoje; arte sobrehumana que arranca do mysterio a verdade, para espalhal-a generosamente, pelo mundo vasto e sombrio, a todos os que gemem e a todos os que choram, como um signal de fraternidade e de esperança.

A occasião é fugidia. Preceito de grande philosophia e de melhor aviso, tão extensa ha de ser a influencia beneffica na vossa carreira e no vosso exito, da sciencia da opportunidade proveitosa mas fugaz. A occasiâo propicia a uma decisão firme e fructuosa. A molestia costuma, ás vezes, velar-se ou negaciar; ha đella ligeiros indicios que o incauto não percebe e que o atilado descobre. Habituareis o vosso raciocinio ao exercicio difficil do presentimento, e,.só assim, raramente ser-vos-ha extranha a passagem fugaz da occasião. Da opportunidade em decidir decorre o acervo na opportunidade da acção, que é o melhor do officio, onde mais esquivo é o momento adequado, durando menos que um instante, exigindo exactidão e presteza para afastar a catastrophe. Nada aconselha a precipitação e o açodamento, mas tudo manda evitar a demora, intoleravel na hora difficil, valendo pelo abandono criminoso quando se anceia pela actividade salvadora.

Pássa rapida a occasião. No conceito popular, adaptado ás vantagen s da existencia, já se manda apanhal-a pelos cabellos. Ter dessa occasião idéa nitida, é o que melhor caracteriza o tino profissional. A ousadia, se conta triumphos inesperados, tambem conhece tremendos derrobos; a timidez escravisa-se ao favor do accaso no fatališmo e na hesitação.

Esfororçai-vois por adquirir a noção da opportunidade que a sorte concede e que a tenacidade tamlbem alcança; della fareis o vosso melhor attributo, conquistado pela energia com que enfrentardes o grande problema do segredo das indicações; a indicação medicamentosa, comedida e adequada, promettendo os maiores successos, a indicação operatoria, fazendo brotar, do espirito de aventura, a dextreza e a serenidade.

A opportunidade da medicação é o maior obistaculo do exercicio profissional. Attendei bem, nem à infantilidade inocua dos semelhanteis, nem a demasia funesta dos contrastes, mas sempre o beneficio dos favoraveis, dentro do dogma soberano que nega ao medico o direito de commandar a natureza, concedendo-lhe a honra de preparal-a, e de assistil-a. Tampouco ninguem a afastará da congruencia na execução do feito cirurgico, exigindo as mais apuradas qualidades de fidalguia, a exactidão do acto, o rigor do traje, a opulencia do local, o exaggero do alinho, a elegancia do gesto, a certeza do triumpho e a alma do artista.

Fugi da indecisão, mesmo que ella se utilize do nome da pruden. cia e, assim denote grandeza com fóros de sagacidade. E' certo que, 
por incapacidade em apprehender a accasião que fóge, póde valer o conceito dos que se embuçam na virtude do precautado e que, com a bonhomia de uma pretendida experiencia velha, sorriem desdenhosamente á ainceridade dos afoutos. Esta inutilidade, ornamentada e orgulhosa, junto do caso grave, só pensa na sua reputação e nos seus proventos e defende-os com a inencia palavrosa e fatua, temerosos da responsabilidade. Não pesa, porém, sobre a decisão honesta e exacta, a sentença foffa dos bonzos. tão postiça têm elles a autoridade impressionante na exteriorisação e no aspecto, apenas solbre a eimplicidade dos rusticos.

Para sorprender a occasião evitai o conselho e o concilio: o conselho poucas vezes é verdadeiro, o concilio é fatalmente confuso e antaigonico. Apurai, porém, a observação do erro proprio e do alheio, evitando o dissabor das repetiçõed. Reconhecendo o proprio erro educais o espirito e áperfeiçoais o entendimento; notando 0 alheio, principalmente o erro dos pontifices, tereis encontrado o unico meio de aprovepitar o aviso sincero de uma velha pratica que melhor instrue no desacerto do que na ostentação.

A experiencia é enganadora. A maldição hippocratica acompanha, até hoje a arte e os seus servidores. A experiencia engana nas suas promessas e na sua finalidade, porque a fantaia se compraz em perturbar um pouco o discernimento... O facto é, sem duvida, indestructivel; mas o facto integral; inatacavel, perfeito, evidente, вó de longe em longe é sorprehendido e acclạmado. Até alcançar tal perfeição atravesse-se uma longa aénie de decepções e de desenganos, por onde a verdade é quasi uma convenção, o credo de um desejo, feito a.o sabor da vontade, em torno de ficções que o prestigio impõe e a lisonja aceita creada no sonho em que uma vida inteira se exgota, febril, captiva e delirante. E' o vicio da abstracção, da ancia do descobrimento.

Nefasta experiencia a que se isola no dogmatismo e repelle a razão como hostil á sua inffalibilidade, principalmente quando, applicada ao onganismo doente, julga governar, de longe, o processo morbido, explical-o, conduzil-o pregando a supremacia da prova do leboratorio sobre a lição da clinica, esquecida de que a medicina, no conceito de Claude Bernard, deve partir do doente e a elle reverter. Tudo indica a prevenção contra a verdade despotica e cruel, porque o commum é velía oofffer o martyrio da perseguição até suavemente vencer a teimosia dos anachronicos e dos retrogrados.

Convém não esquecer o principio da experiencia fallaz, antes de tudo para uso pessoal. Nenhuma restricção mais necesøaria do que a que dilue os desvaneios proprios pois a vaidade costuma exaltar a imaginação e conduzir ao delirio; nenhum defeito mais perigoso do que a intransigencia, tanto a presumpção castiga permittindo a 
alucinação do vulto, quando a realidade é deformante; nada ma1s lamentavel do que a convicção de sabedoria porque o acaso impiedoso abala sempre a soberba dos nescios.

E' precieo eyitar o enthusiasmo pela invencionice alheia, ne certeza de que ninguem abdica de sua faculdade de discernir, respeitando-a pela sulbmissão sem deturpal-a pelo dominio. O utilitarismo é hoje doutrina, o chegadismo já é religião. Meios, recursos, enøcenação, apparenicias, calculos, tudo serve para a rapida conquista das grandes e proveitosas posições. A invenção espalhafato, a descoberta intrujice, a ideia lentejoula, são methodos de todo o tempo, aperfeiçoados pela concurrencia. A boa fé paga desta fórma, pesado tributo á esperteza que logra longamente ser genialidade, á astucia que se cobre de grandeza, lá mediocridade que chega a ser sciencia, a fatuidade que consegue ser ponderação.

A experiencia tem cabellos brancos; deve assim ser tamibem o experimento que todos querem amadurecido e certo, ponderado e seguro, acertado e tranquillo, para que um pouco de vercdde não ce amplie em um excesso de imaginação. Raramente o principio basico ou o facto indestructivel são surtos do improviso, ligam-se sempre ás reflexões e ao tempo, á sabedoria e á prova. Ha de certo a centelha do genio, ás vezes illuminando desesperadamente o tritho de ideias novas, mas tambem offuscando e deslumbrando a ponto de perturbar a visão perfeita e calma. São estes deslumbramientos que provocam a cegueira dos icontemporaneos rebaixando-os ao fetichiemo e á idolatria que a posteridade não perdoa. O juizo é difficil. Difficil por tralbalhoso será a juizo que desvenda o diagnostíco indeciso e vago. A humana contingencia do erro tolda as scintillações do raciocinio na luta com o desconhecido que tantas vezes é o mylaterio da molestia. Embora grande o poder da intelligencia adestrada e firme, robustecida na olbservação perfeita e continua, não se eliminará o erro nem se apagará a duvida. O diagnostico é o mais subtil trabalho de ideação; signaes e symptomas procedem da diversidade e exteriorizam-tse nas variantes: a objectivação mascara, esconde, altera o feito do mal embaraçando a razão hesitante ; o subjectivismo perturba involuntariamente o aspecto da molestia. O prognostico é a magia da arte, quasi dom de divindade, attributo de inspirado, visão que o tempo aguça e à experiencia aprimora; por isøo mesmo, é graça dos escolhidos, de que a medicina criteriosa habitualmente se afasta para fugir ao dissabor da zombaria.

Muitas vezes o diagnostico será inaccessivel; honrareis melhor a difficuldade com a confilsão de deficiencia do que com o subterfugio de meia palarra ou a sagacidade do emibuste. Porque é primacial a regra da simplicidade; a decisão não lucra em força se a 
phrase é pomposa e a physionomia majestaatica. Simples serão os habitos e ob conceitos para que o erro, inevitavel e universal, não tenha o fragor dos granides desmoronamentos com que a impiedado da critica se desforra dos dogmaticos e dos arrogantes. Mesmo na hora de maior difficuldade, nada como o pensar simples, evocando sempre o erro e seu ensinamento, sentindo que a perspicacia leva quasi á perfeição, onde só se chega pela vontade e pelo exiforço, as virtudes dos homens aimples.

O juizo tamıbem é difficicil por ser exigente. Já não é mais o juizo proprio, mas o julgamento alheio que dá preferencias, vota abbandonos, decide condemnações. Talvez delle não tenha cogitado o aphorismo hippocratico, mas o exercicio profissional sente-o todos os dias e é habito, infelizmente, desejal-o transigindo, condescendendo, capitulando mesmo. Na medicina, como em qualquer carreira, o favor da opinião é caprichoso e vae-se accessivel por muitos caminhos, franicos e virtuosos, abertos e escusos, legitimos e acertados. Não ha regrạ̣ que ensinem a licitar o apoio do conceito publico senão aquelle em que se fortalece o impeto de uma amibição honesta. São regras inflexiveis, inherentes á honra pessoal, talvez já tidas como inutệ́ ou desusadas, depois que o renome é distribuido tarito ao trabalho como á ousadia, á sinceridade e ao ardil, á energia e ao atrevimento, á sabedoria e á impostura. Sentireis como este confronto inevitarel deprime e diminue, e o vosso protesto, pela connivencila doe máos e a covardila silenciosa dos timidos, póde crear-vos o risco de uma reputação acabrunhadora de insanidade.

o juizo tambem é diffícil quando é o conceito de hostilidade impiedosa, enfunada, doutoral, interesseira; juizo dipficil, incontentavel, destruidor, imposto pelas exigencias da competição e pelo deøespero da concurrencia. O homem do effeito tem severidades doentias, lembradas pela inveja para diminuir os tormentos e as torturas que a fortuna alheia costuma suścitar. Na mais aprazivel das effusões póde haver uma cilada: tem-se encontrado todas as perversidades nas mais aiffectuosas das palavras, todas as insidiae no trato maís ameno. Esse juizo tem modulações; é o murmurio surdo e pertinaz, a maledicencia occulta e incansavel, a propaganda licita e injuriosa, o commentario anonymo e falso, a diecussão feroz $\theta$ odienta. Têm os seus aspectos; é a divulgação do erro, o regosijo pela falta, a noticia do ineuccesso, a calumnia sobre o irreparavel, a campanha do descredito, o ongulho da maldade, a satisfacção pela decadencia... $\mathrm{E}$ têm as suas recompensas: os applausos e a lisonja, tributo dos amedrontados, que se previnem contra a odiosidlade da critica repugnante com a força de subserviencia.

Numa vida tão curta, ưma arte tão longa - tal é a extensão 


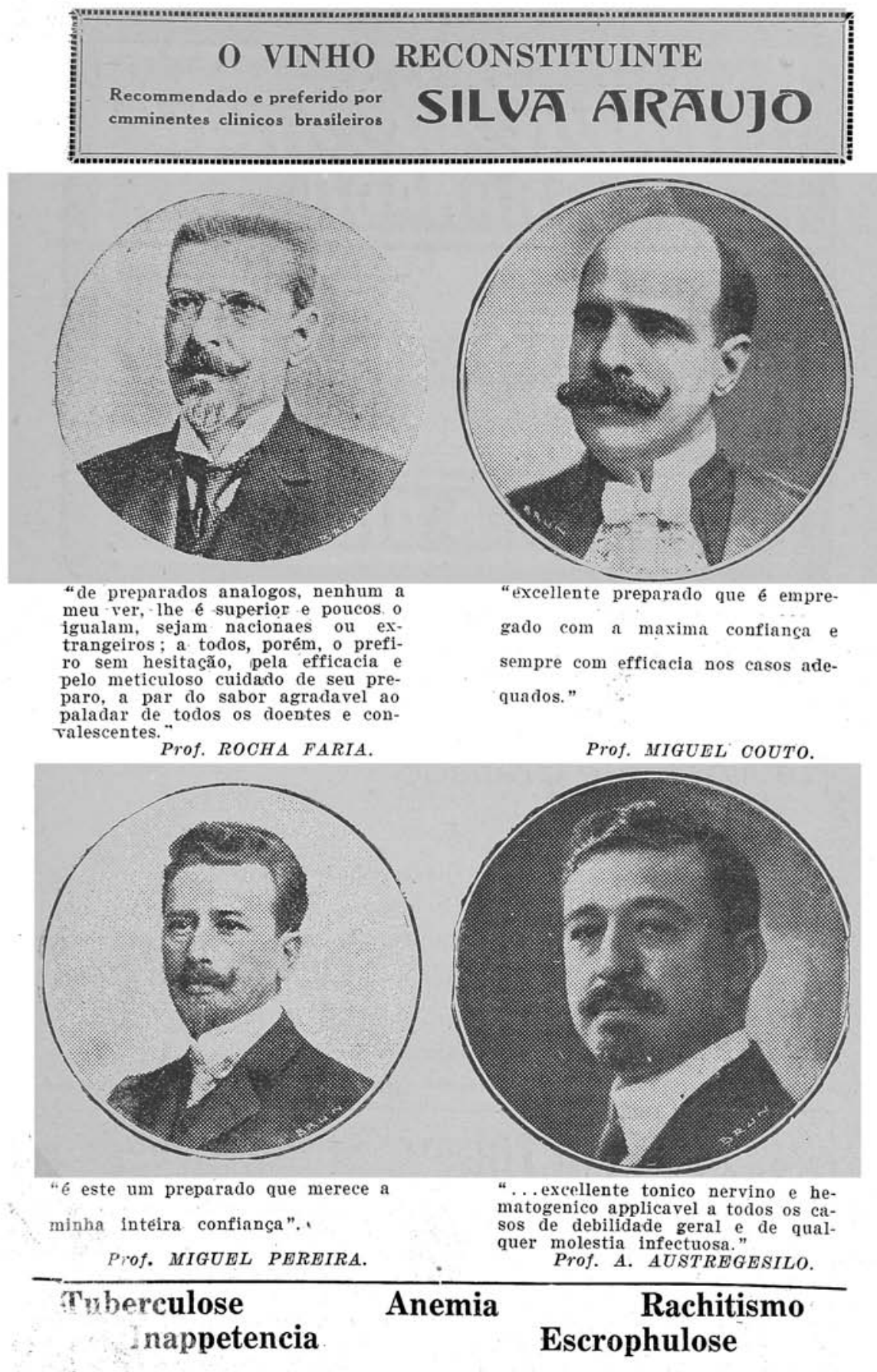




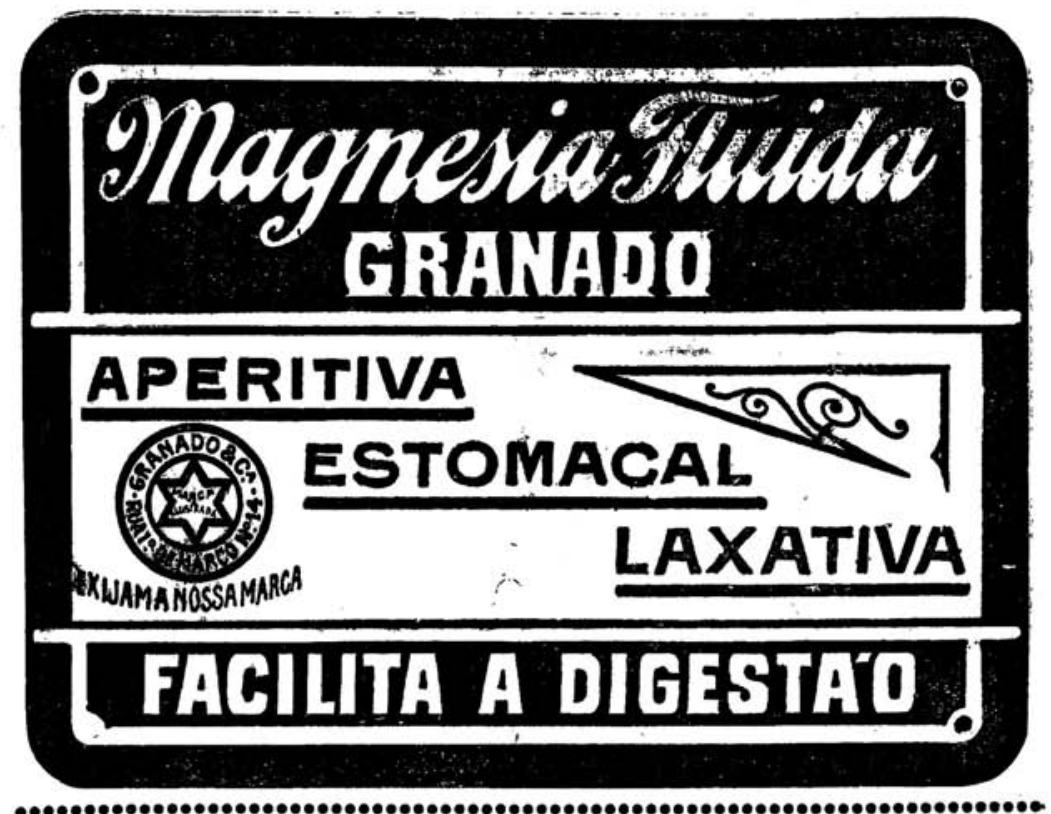

Anemia - Neurasthenia - Depressões Nervosas Fraqueza geral - Convalescença

Nevrostenil Granado

Sôro Neuro-tonico ntensivo

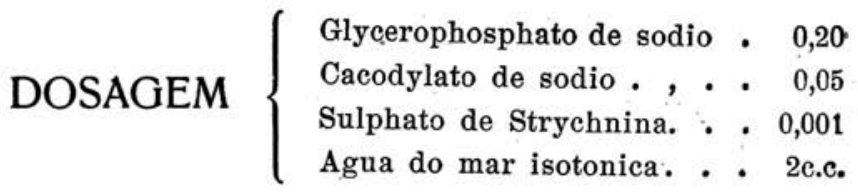

2 c. c. diariamente em injeç̧ões subcutaneas ou intramusculares. Series de 12 injecções com 6 a 8 dias de repouso.

$\bullet T V I T$ TITI $\bullet \quad$ COMPRIMIDOS \& GRANULADO

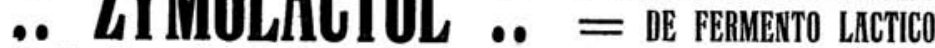

Realizando a anfisepsia do Infestino, o seu emprego esfá perfeifamente indicado nos casos de Infecçāo intestinal. Enterites (agudas e chronicas), Febre typhoide, Grippe, efc. - Uffllissimo nas Perfurbaçōes funccionaes do figado e rins e Afecçōes da pelle. - ExIjam sempre ZYMOLACTOL (Comprimidos ou granulado)

Depositarlo João Lopes $\begin{aligned} & \text { Rua } 11 \text { de Agosfo, } 85 \\ & \text { SÃ̃ PAUbO }\end{aligned}$ 
da vossa tarefa. Para lograr o momento fugaz só o juizo difficil que se apoia na experiencia enganaldora - eis a intensidade do. vosso esforço.

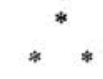

Não eei se conheceis o ceremonial na investidura da medicina,. em tempos longinquos, entre os barbaros hindús. 0 postulante. offerecia o dorso robusto ao salcrificadior, para ahi abrir-lhe duas. largas fen'das, dando passagem á trave de madeira que o suspenia do sólo. Punham-lhe, então, nas mãos o livro sagradio dos remedios pesando dez kilos e o paciente provava a vocação conservando o fardo precioøo, durante a prova tremenda, insensivel á dor torturante.

Não se pede mais mantyrio de tal especie aos contemporaneos, mas é permittido lamentar terem transformado a vocação em negocio e o medico de profissão em medico de industria. A iniciação faz-se hoje quasi øem ritual; o compromisso, para muitos, é um acto inconsciente, depois que o texto em latim torna incomprehensiveis o alcance e a perfeição da promessa. O juramento hippocratico não é mais a formula universal. Hoje só a Faculdade Catholica de Lille é que leva os novoo medicos ao altar, mandando-os. jurar que serão instruildos na pratica, dextros na arte e honestos. na vida. Bella tradição essa que obriga o medico a abandonar $o$ cynismo e a cultuar o caracter, tão triste é prescindir-se da lei moral, quando os codigos não pódiem abranger as faltas da consciencia.

Todo medico tem de ser um homem de virtudes. A primeira destas virtudes é a Justiça, o respeito aos direitos alheios, o respeito á vida e á honra do nosso semelhante. Depois é o altruismo que firma a nossa solidariedade com o enfermo, fazendo nossa a alegria pela saude que renasce e nossas as lagrimas pela vida que se extingue. E' a dedícação o maior dos nossos encargos e a meYhor das nossas honrarias, por tal forma pertencemos a quem preciøa de nossa solidariedade ennolbrecida no ministerio sagrado. E' a coragem, adoçando os pezares e as magoas, o terror e a morte; coragem para desafiar o contagio, vencer a repugnancia, seguir o soffrimento, ladear a desgraça, acompanhar a dor. E' a paciencia que á irritação e ao desanimo da doença offerece o carinho da palavra e a piedade do consolo. E' o desinteresse que ordena o gesto nobre do estender a mão para receber a paga do trabalho honesto, mas repelle o calculo de promipta independencia, feito antecipadamente sobre a herança dos moribundos. E' a discreção para os segredos do corpo e da alma. E' a sciencia confiando na consolação e na cura. E' a dignidade que exige o culto deste prestigio mille- 
nario de que falla a escriptura, mandando honrar o medico por amor á necessidade, porque Deus o creou á elle. E' a honestidade que confundirá os mercadores do templo, iniciados em fraude e acabados em charlatanice aventureira que devassa a intimidade do lar, destróe o encanto da familia, corrompe os costumes, estimula o crime, explora a fragilidade dos homens, assalta o brio, devassa o pudor, anniquilla a vida alvorescente; os que ganham o pão na truanice, rufam no preconicio desmesurado, corvejam sobre os deśpojos da victima; as figuras sinistras que a profissão tolera pela attitude aviltante que escolhem, revivendo a audacia perigosa dos innovadores, ostentando a omnipotencia dos mesinheiros, eternizando a raça execranda dos traficantes e a miseria repulsiva dos dissolutos.

Pouco tempo mais, e tereis de seguir o caminho penoso da nova vida. Não esqueçais que ella tem tanto do sacerdocio como da profissão; sereis daquelles homens, de que falla a magica sciencia da idade média, perfeitos de corpo e melhores de alma. Tallvez vos sejam sabidos os clamores da crise e da indigencia embaraçando o exercicio da boa arte de curar. Razões de solbra têm os que lamentam que o offficicio não seja lucrativo e, do vosso espirito não se desfaça nunca a certeza de que, se procurais a abastança, outro deve ser o rumo da vossa actividade. O que determina o pauperismo profissional é a falta de unç̧ão vocativa que obriga o sacrificio, impõe o trabalho $e$ exige a coragem. A indolencia e a tibieza preferem atordoar-se no tumulto das grandes collectividades, abri go dos perturbadores do bom costume e do pensamento puro. Se me ouvirdes eu apontarei esse caminho como o da dissolução, onde o sacerdocio talvez seja lapidado por anachronico, decrepito, ridiculo ou visionario.

Não vos faltará, porém, onde militar nobremente na profíssão. Olhai a nossa terra, tão grande e tão harmoniosa; segui a estrada de sua conquista e de sua civilisação. Ide, como serventuarios de uma grande fé, na missão de evangelizar com o exemplo e de prégar a sabedoria. Contra esta terra, formosa e ridente, ha o labéo de monbidez maculando o deserto das maravilhas com o homem desprotegido, raro e doentio. Não bastará, na catechése da cura e da eugenesia, corrigir os males do corpo, tão generosa tambem é a iniciativa de illuminar o espirito escurecido na indifferença $\theta$ na ignorancia. No mister da vosisa profissão sereis of semeadores da boa palavra e da boa doutrina, dareis vigor ao combalido; força ao inerme, saude ao doente, alento ao fraco, ensino ao inculto, crença ao insensivel opinião ao inutil, liberdade ao individuo, consciencia ao cidadão.

Uma vez, fallando a outros como vós, disse o que vos repito agora. Não vos serão eternamente propicios $\sigma_{\mathrm{s}}$ dias que vos espe- 
ram, não faltará onde desfallecer a vossa coragem, entibiar-se o vosso animo, esmorecerem as voøsas energias. Só vos poderão valer como arrimo o amor á prớissão que escolherstes e a vossa con6ciencia. Esta será o melhor refugio dos dias tristes, offerecendovos agasalho e segurança na hora dolorosa das grandes tempestades: o amor á profissão conduzirá á santidade pelo martyrio voluntario do devotamento. Conservai-as na mesma pureza, tão limpa e tão serena deve ser a vossa consciencia como o amor á vossa vida.

Não vos quiz dar uma lição, senão fazer sentir uma verdadeira Venderde que de certo ha de açular os vossos maiores surtos de vontade victoriosa, e tanta é a certeza que nutro do vosso vigor que, propositadamente, contei a rudeza da profiøsão que escolhestes para servil-a e ennobrecer-vos. Esbocei os vossos grandes trabalhos, apontei-vos os labores do futuro. Era esta a fórma de que se servia Ch. Wagner, o velho e mystico pastor protestante, quando pensava no apenfeiçoamento nela tranquilla persipectiva das attribulações. E' delle o episodio edificante daquelle dia de inverno brumoso e funereo. A terra toda envolvia-se na nevoa triste; de perto, mal se advinhavam os tectos e as arvores, de longe nada mais. Vozes humanas, tropel de animaes, rodar de carros, o silvo. das locomotivas, a orchestração toda do trabalho, apagava-se na sombra do nevoeiro denso. Nem um raio claro, nem um som vibrante; sómente lugubres impressões como serão as do fím da terra quando o sol moribundo não puder dissipar mais a escuridão da noite. Um homem entrevára o espirito na contemplação da natureza funebre, e, cheio de pensamentos turvos, caminhando na desolação de seus pesares, por acaso parou deante de um destes grandes emporios de actividade e de trabalho onde se preparavam os atavios da moda para a proxima estação da primavera fecunda. Sob a futilidade daquelles esplendores frageis, flores, adornos, fitas flammejantes, o triste teve a visão de rostos sorridentes, horizontes azues, caminhos cheios de luz, jardins cheios de sol. Comprehendeu então que haveria ainda bellos dias no futuro e murmurou contrito a oração da gloria dos prophetas que em plena noite predizem a alvorada, e a oração da paz aos que nos offerecem exemplos tão grandes em cousa tão simples. Esperar, ter confiança no que ha de vir, eís o que nos falta; são as fórmas mais puras da fé todos os labores do futuro apezar da figura desanimadora do presente. Ninguem olha esta figura nem muito, nem demoradamente. Cada um, que trabalhe, que semeie, que creia na recompensa, porque todo o pensamento sombrio está eivado de erro. e nunca, nunca, a verdade foi negra. 